\title{
Differential alternative splicing of human transglutaminase 4 in benign prostate hyperplasia and prostate cancer
}

\author{
Sung-Yup Cho ${ }^{1 *}$, Kyungho $\mathrm{Choi}^{2 *}$, Ju-Hong Jeon ${ }^{3}$, \\ Chai-Wan Kim ${ }^{1}$, Dong-Myung Shin ${ }^{1}$, \\ Jong Bouk Lee ${ }^{4}$, Sang Eun Lee ${ }^{4}$, Choung-Soo Kim ${ }^{5}$, \\ Jeong-Soo Park ${ }^{6}$, Eui Man Jeong ${ }^{1}$, Gi-Yong Jang ${ }^{1}$, \\ Kye-Yong Song ${ }^{7}$ and In-Gyu Kim ${ }^{1,8}$ \\ ${ }^{1}$ Department of Biochemistry and Molecular Biology \\ Aging and Apoptosis Research Center (AARC) \\ Seoul National University College of Medicine \\ Seoul 110-799, Korea \\ ${ }^{2}$ Research Institute of National Cancer Center \\ Gyeonggi-do 410-796, Korea \\ ${ }^{3}$ Department of Physiology and Biophysics \\ ${ }^{4}$ Department of Urology \\ Seoul National University College of Medicine \\ Seoul 110-799, Korea \\ ${ }^{5}$ Department of Urology \\ Asan Medical Center \\ Seoul 138-736, Korea \\ ${ }^{6}$ Department of Biochemistry \\ Dankook University College of Medicine \\ Cheonan 330-714, Korea \\ ${ }^{7}$ Department of Pathology \\ Chung-Ang University College of Medicine \\ Seoul 156-756, Korea \\ ${ }^{8}$ Corresponding author: Tel, 82-2-740-8248; \\ Fax, 82-2-744-4534; E-mail, igkim @ plaza.snu.ac.kr \\ ${ }^{*}$ These authors contributed equally to this work. \\ DOI 10.3858/emm.2010.42.4.031
}

Accepted 10 February 2010

Available Online 22 February 2010

Abbreviations: $\mathrm{BPH}$, benign prostate hyperplasia; $\mathrm{PCa}$, prostate cancer; PSA, prostate-specific antigen

\footnotetext{
Abstract

Transglutaminase 4 is a member of enzyme family that catalyzes calcium-dependent posttranslational modification of proteins. Although transglutaminase 4 has been shown to have prostate-restricted expression pattern, little is known about the biological function of transglutaminase $\mathbf{4}$ in human. To gain insight into its role in prostate, we analyzed the expression status of human transglutaminase 4 in benign prostate hyperplasia (BPH) and prostate cancer ( $\mathrm{PCa}$ ). Unexpectedly,
}

RT-PCR and nucleotide sequence analysis showed four alternative splicing variants of transglutaminase 4: transglutaminase 4-L, -M (-M1 and -M2) and -S. The difference between transglutaminase 4-M1 and -M2 is attributed to splicing sites, but not nucleotide size. The deduced amino acid sequences showed that transglutaminase 4-L, -M1 and -M2 have correct open reading frames, whereas transglutaminase 4-S has a truncated reading frame. RT-PCR analysis of clinical samples revealed that transglutaminase 4-M and -S were detected in all tested prostate tissue (80 BPH and 48 $\mathrm{PCa}$ ). Interestingly, transglutaminase 4-L was found in $56 \%$ of BPH (45 out of 80 ) and only in $15 \%$ of $\mathrm{PCa}$ (7 out of 48). However, transglutaminase 4-L expression did not correlate with serum prostate-specific antigen (PSA) level, prostate volumes or PSA densities. These results will provide a clue to future investigation aiming at delineating physiological and pathological roles of human transglutaminase 4 .

Keywords: alternative splicing; prostate hyperplasia; prostatic neoplasms; transglutaminase 4

\section{Introduction}

Transglutaminases are a family of calcium- dependent enzymes that consist of eight isoenzymes (transglutaminase 1-7 and factor XIIla) and one evolutionary related protein (Band 4.2; Lorand and Graham, 2003). They participate in a variety of biological phenomena associated with tissue protection, such as skin differentiation, blood coagulation and wound healing processes. During these processes, transglutaminases produce a high molecular weight of protein architecture conferring a resistance to mechanical stresses and proteolytic degradations (Griffin et al., 2002). The protein architecture is composed of protein polymers covalently crosslinked by isopeptide bond formation between peptide-bound glutamine and lysine residues.

A number of studies concerning the nature of postejeculatory plug have recognized that a transglutaminase isoenzyme secreted from prostate gland plays an important role in the reproduction biology of rodents (Williams-Ashman et al., 1972, 1977; Williams-Ashman, 1984). Following studies have identified that copulatory plug is formed by transglutaminase 4 (prostate transglutaminase or 
TGP), a highly glycosylated protein enriched in dorsal prostate of rodents (Seitz et al., 1990). Interestingly, analysis of amino acid sequence determined by molecular cloning showed no putative signal sequence required for secretion ( $\mathrm{Ho}$ et al., 1992). The copulatory plug formation has been thought to facilitate the fertilization by preventing seminal fluid from leaking out of vagina (Cukierski et al., 1991). In addition, transglutaminase 4 has been suggested to play an important role in suppression of sperm antigenicity in the female genital tract via incorporating seminal protein, such as uteroglobin, or polyamines into sperm cell surfaces (Mukherjee et al., 1983; Paonessa et al., 1984).

In contrast to rodent transglutaminase 4 , little has been known about physiological roles of human transglutaminase 4 . Previous studies revealed that human transglutaminase 4 showed prostate-restricted expression pattern (Dubbink et al., 1999), raising a possibility as a novel target for prostate-related diseases, particularly in prostate cancer, the second leading cause of cancer death in men (Savli et al., 2008). Interestingly, no expression of human transglutaminase 4 was observed in some prostate cancer cell lines (Dubbink et al., 1996), even though its promoter was shown to have basic transcriptional activity (Dubbink et al., 1998). Transcript analyses have showed that the expression of human transglutaminase 4 is reduced in most metastatic prostate cancer specimens (An et al., 1999). Recently, knockdown of transglutaminase 4 reduced invasive capacity in prostate cancer cells (Davies et al., 2007). Altogether, these results may provide helpful clues to understanding the role of human transglutaminase 4 in prostate cancer.

Alternative splicing is an important mechanism to increase structural and functional diversity of proteins (Blencowe, 2006). In addition, growing evidence indicates that splicing variants can provide diagnostic and/or therapeutic targets for several cancers (Pajares et al., 2007). In this study, we found four mRNA variants of transglutaminase 4 in human prostate tissues. Sequence analyses were carried out to demonstrate alternative splicing of transglutaminase 4 . We also analyzed alternative splicing pattern in the tissue specimens obtained from benign prostate hyperplasia (BPH) and prostate cancer $(\mathrm{PCa})$ patients.

\section{Results}

\section{Identification of human transglutaminase $\mathbf{4}$ isoforms}

We initially used a RT-PCR method to examine the

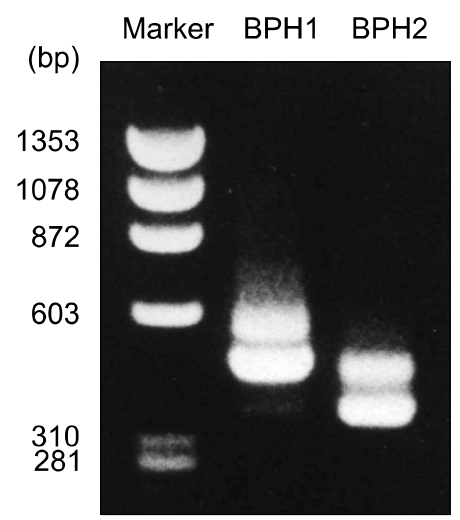

Figure 1. Identification of human transglutaminase 4 spliced variants in $\mathrm{BPH}$ tissues. RACE was performed on CDNA synthesized from BPH samples and resulted in three different-sized PCR products, $350 \mathrm{bp}, 450$ bp and $600 \mathrm{bp}$.

expression of human transglutaminase 4 in $\mathrm{BPH}$ tissues. Unexpectedly, three different RT-PCR products were found in the tissue samples (Figure 1). While a $450 \mathrm{bp}$ fragment was the predicted size of band based on the sequence of human transglutaminase 4 cDNA (Grant et al., 1994; Dubbink et al., 1996), two products of $600 \mathrm{bp}$ and $350 \mathrm{bp}$ were the unpredicted sizes.

In order to assure the identity of each RT-PCR product, these fragments were cloned into pT7Blue vector. Sequence analysis revealed that a $450 \mathrm{bp}$ fragment actually contains two different coding sequences of human transglutaminase 4 , transglutaminase 4-M1 and -M2 (Figure 2A). The sequence of transglutaminase 4-M1 was completely identical to that of human transglutaminase 4 as reported previously (Grant et al., 1994; Dubbink et al., 1996). The sequence of transglutaminase 4-M2 was identical to that of transglutaminase 4-M1 with exception of a 4 bp segment (GTGA) insertion (Figure 2A, underlined). This insertion leads to a +2 frameshift, resulting in premature termination after six amino acids. However, interestingly, there are three consecutive initiation codons in the $5^{\prime}$ end sequence (Figure 2A). It is thus possible that the reading frame of transglutaminase 4-M2 can be restored by alternative translation initiating at the third ATG codon.

A $600 \mathrm{bp}$ fragment (transglutaminase 4-L) also had coding sequences of transglutaminase 4 . However, transglutaminase 4-L containing novel $135 \mathrm{bp}$ sequences (positions at 7447-7581 in Figure $3 \mathrm{~A}$ ), compared to transglutaminase 4-M1. The sequence of transglutaminase 4-L except an additional $135 \mathrm{bp}$ fragment was completely identical to that of transglutaminase 4-M1. This insertion did not interfere with open reading frame of transglutaminase 4-M1, thereby providing addi- 
A $\begin{array}{lcccccccccccc}* & * & M & D & A & S & K & E & L & Q & V & L & H \\ \text { ATG } & \text { ATG } & \text { GAT } & \text { GCA } & \text { TCA } & \text { AAA } & \text { GAG } & \text { CTG } & \text { CAA } & \text { GTT } & \text { CTC } & \text { CAC }\end{array}$ TG4-M2

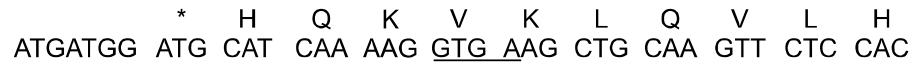

B

1 MMDASKELRS HFVAQAGVLW LFTAAIIAHC SLKLLGSSDS PTSVSRVTGI TELQVLHIDF 61 LNQDNAVSHH TWEFQTSSPV FRRGQVFHLR LVLNQPLQSY HQLKLEFSTG PNPSIAKHTL 121 VVLDPRTPSD HYNWQATLQN ESGKEVTVAV TSSPNAILGK YQLNVKTGNH ILKSEENILY 181 LLFNP

C

1 MMDASKELQV LHIDFLNQDN AVSHHTWEFQ TSSPVFRRGQ VFHLRLVLNQ PLQSYHQLKL 61 EFSTGHSGCH QFPQCHPGQV PTKRENWKPH P•

Figure 2. Comparison of nucleotide and amino acid sequences of human transglutaminase (TG) 4 isoforms. (A) Transglutaminase 4-M2 has four more nucleotide (GTGA, underlined) compare to transglutaminase 4-M1, which results in frameshift. Among three consecutive initiation codons (ATGATGGATG), transglutaminase 4-M1 is translated from first and transglutaminase 4-M2 is from third initiation codon. (B) Deduced amino acid sequence of transglutaminase 4-L. The underlined 45 amino acids are found only in transglutaminase 4-L, not in transglutaminase 4-M or -S. (C) Deduced amino acid sequence of transglutaminase 4-S. Transglutaminase 4-S shows 107 nucleotide deletion compared to transglutaminase 4-M1 and encodes truncated protein comprising 91 amino acids.

tional coding sequences. Thus, the open reading frame of transglutaminase $4-\mathrm{L}$ can encode the polypeptide composed of 723 amino acid residues, indicating that transglutaminase $4-L$ has 45 additional amino acid residues (Figure 2B), compared to transglutaminase 4-M1. By contrast, sequence analysis of a $350 \mathrm{bp}$ fragment (transglutaminase 4-S) showed that 107 nucleotides were deleted from the transglutaminase 4-M1. This deletion caused in a shift of reading frame, leading to generating a stop codon (TGA). Thus, the open reading frame of transglutaminase 4-S may encode a prematurely terminated protein con- sisting of 91 amino acid residues (Figure 2C).

\section{Alternative splicing of the human transglutaminase 4 gene}

To investigate how human transglutaminase 4 isoforms are generated, we next analyzed the genomic structure of human transglutaminase 4 based on its sequence information obtained from human genome resources of NCBI. As shown in Figure $3 \mathrm{~A}$, the $\mathrm{NCBI}$ database shows that human transglutaminase 4 gene consists of 14 exons and 13 introns and spans about $40 \mathrm{~kb}$ of genomic DNA

A

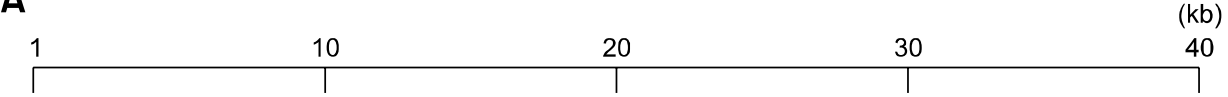

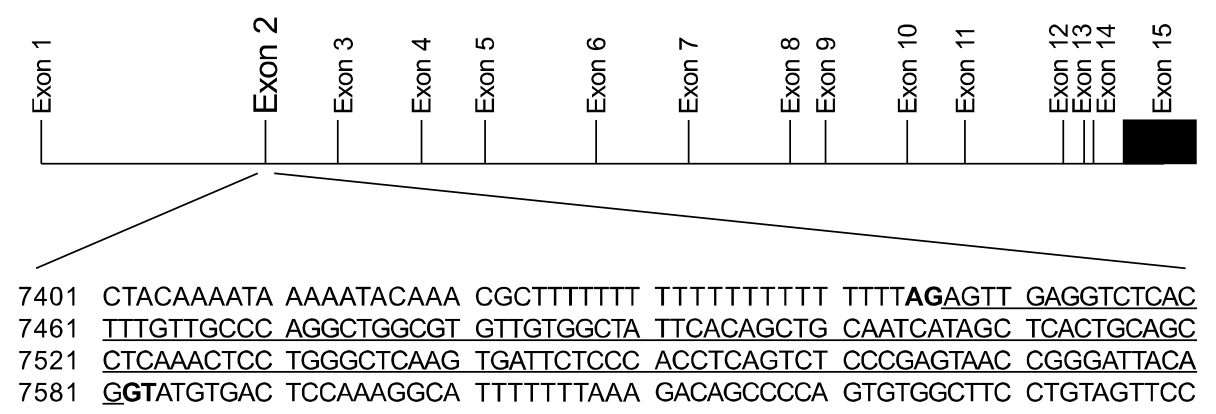

B

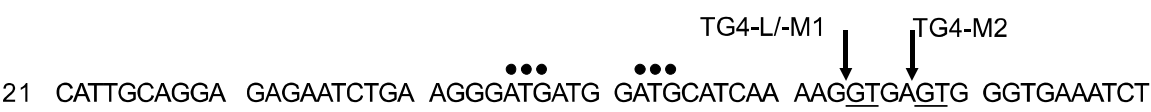

Figure 3. Structure and alternative splicing of human transglutaminase (TG) 4 gene. (A) Human transglutaminase 4 gene has 15 exons and 14 introns. Exon 2, containing 135 nuclotides, is found only in transglutaminase 4-L and Exon 4, comprising 107 nucleotides, is deleted in transglutaminase 4-S. (B) Nucleotide sequences of the exon-intron junction between exon 1 and intron 1. The splicing site of transglutaminase $4-\mathrm{M} 2$ is four-nucleotide apart from the site of transglutaminase 4-L and $-M$. The dots above the nucleotide sequences indicate initiation codons. 


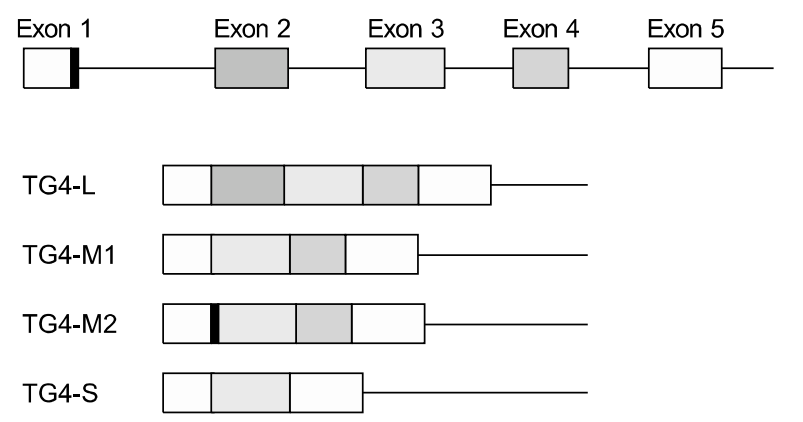

Figure 4. Schematic representation of alternatively spliced transcripts for human transglutaminase (TG) 4.

on chromosome 3p21.33-p22 (region 44,891,131$44,931,097)$. Sequence alignment revealed that the novel $135 \mathrm{bp}$ sequences of transglutaminase $4-L$ is exactly matched with sequences on the intron 1 in NCBI database. Interestingly, putative splicing acceptor and donor sites were found in flanking region of the novel $135 \mathrm{bp}$ sequences of transglutaminase $4-\mathrm{L}$. Thus, this finding indicates that a $135 \mathrm{bp}$ fragment is a novel exon (designated as Exon 2 in Figure 3A) of transglutaminase 4 . The nucleotide sequences of the exon-intron junction in the exon 2 showed that splice donor and acceptor sites followed the GT/AG rules (Mount, 1982).

In a region of intron 1 splice donor sequence, two potential splicing junction consensus sequences were found in proximity. The transglutaminase 4-M1 was spliced at a G/gt consensus site (Figure 3B). In contrast, transglutaminase 4-M2, spliced at
A/gt (Figure 3B), included the 4 nucleotides (GTGA) after the splice junction, resulting in shift of reading frame of transglutaminase 4-M2 form. Thus, the transglutaminase 4-M1 and -M2 forms are generated by selection of two consecutive splice consensus sequences located at intron 1. On the other hand, the exon 4 contains the $107 \mathrm{bp}$ corresponding to the exact sequences that are deleted in transglutaminase $4-S$. The schematic representation of alternative splicing of transglutaminase 4 gene is illustrated in Figure 4. These results showed that exon 2 and 4 are responsible for the expression of the transglutaminase $4-\mathrm{L},-\mathrm{M}$ and $-S$. In order to exclude the possibility of existence of different alleles, exon 2 and 4 were analyzed by PCR. Neither exon 2- or 4-deficient allele could be found in 100 normal human genomic DNA samples (data not shown).

\section{Expression of transglutaminase 4 isoforms in yeast and HeLa cells}

To examine whether each transglutaminase 4 isoform is translated properly, hemagglutinin (HA)tagged transglutaminase 4 isoforms were cloned to pYes2.0 vector and expressed in yeast INVsc1 cells. Western blot analysis showed that transglutaminase 4-L, -M1 and -M2 forms were expressed as single proteins and estimated molecular weights were $93 \mathrm{kDa}$ for transglutaminase 4-L and $89 \mathrm{kDa}$ for transglutaminase 4-M1 and -M2 (Figure 5A). In addition, yeast extract transformed
A

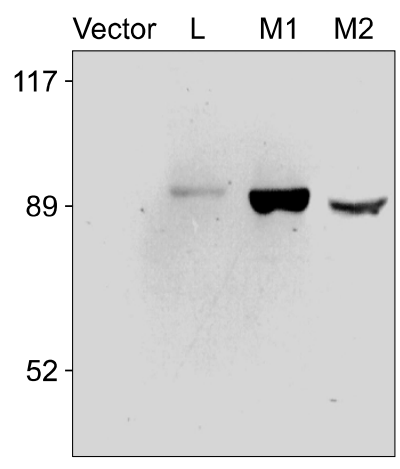

B

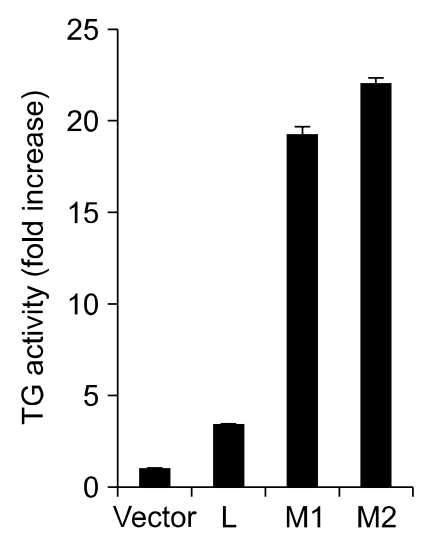

C

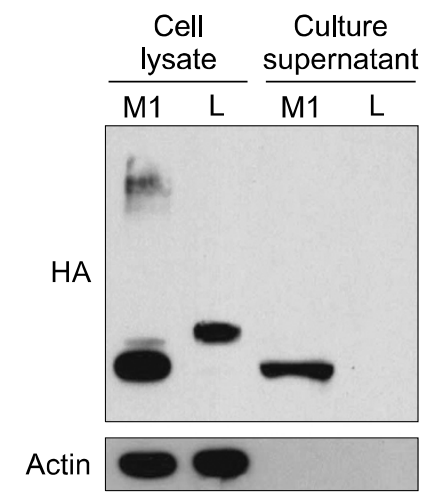

Figure 5. Characterization of transglutaminase 4 isoforms expressed in yeast and HeLa cell lysate. (A) Yeast INVSc1 cells were transformed with pYes2.0 vector containing cDNA for hemagglutinin-tagged transglutaminase 4 isoform. Yeast lysates were analyzed by Western blot analysis using anti-hemagglutinin antibody. (B) transglutaminase activities of yeast lysates were estimated by measuring incorporation of $\left[{ }^{14} \mathrm{C}\right]$-putrescine to $\mathrm{N}, \mathrm{N}^{\prime}$-dimethylcasein. Fold increase of transglutaminase activity is expressed as a relative value to that of vector transfected cells, which was normalized by protein level of transglutaminase 4 isoforms. (C) HeLa cells were transfected with cDNA for hemagglutinin-tagged transglutaminase 4 isoforms. Cell lysates and lyophilized culture supernatants were analyzed by Western blot analysis using anti-hemagglutinin antibody. L, transglutaminase 4-L; M1, transglutaminase 4-M1; M2, transglutaminase 4-M2. 


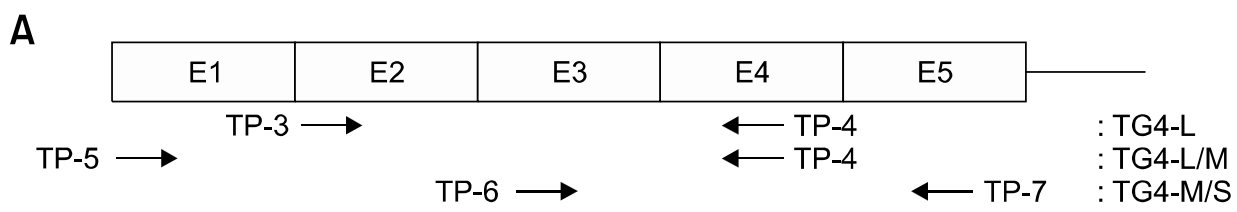

B

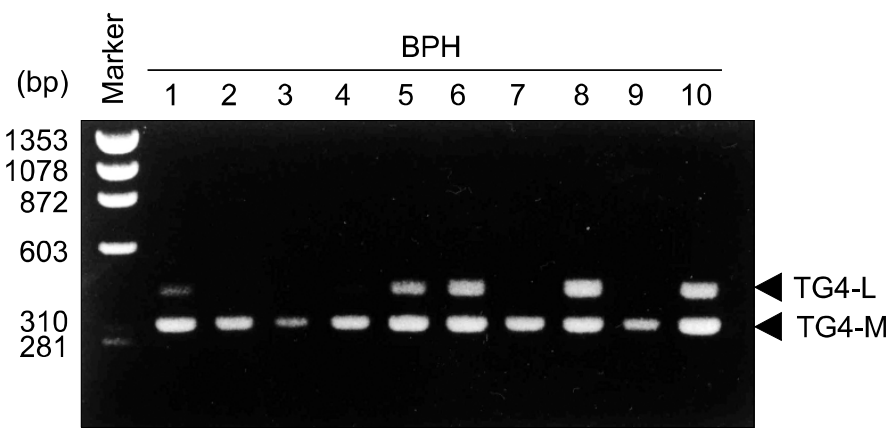

Figure 6. Expression of human transglutaminase (TG) 4 isoforms in $\mathrm{BPH}$. (A) Localization of primers used to amplify each spliced variants of human transglutaminase 4. (B) Representative of RT-PCR analysis for transglutaminase 4 isoforms. CDNA synthesized from BPH tissues are amplified with TP-5/TP-4 primers to detect transglutaminase $4-L$ and $-M$ isoforms.

with each transglutaminase 4 isoform exhibited significant transglutaminase activity compared to vector-transformed yeast extract (Figure 5B). Transglutaminase 4-L and transglutaminase 4-M1 were also expressed as hemagglutinin-tagged forms in HeLa cells and detected as single protein in cell lysate. Interestingly, only transglutaminase 4-M1 were detected in lyophilized culture supernatant (Figure 5C), suggesting that transglutaminase 4-L was not secreted.

\section{Differential alternative splicing of transglutaminase 4 in $\mathrm{BPH}$ and $\mathrm{PCa}$ specimens}

The expression of transglutaminase 4 mRNA isoforms was analyzed in prostate tissues by RT-PCR. The cDNAs were amplified using three pairs of specific primers designed to amplify only the transglutaminase 4-L form (375 bp with TP-3/TP-4), transglutaminase 4-L and $-\mathrm{M}$ forms (449 bp and $314 \mathrm{bp}$ with TP-5/TP-4), and transglutaminase 4-M and -S forms (441 bp and $334 \mathrm{bp}$ with TP-6/TP-7), respectively (Figure 6A). Clinical parameters obtained from patients diagnosed as
$\mathrm{BPH}$ or $\mathrm{PCa}$ were summarized in Table 1. RT-PCR analyses revealed that both transglutaminase 4-M and $-S$ were detected in all tested tissues (80 BPH and $48 \mathrm{PCa}$ tissues). Transglutaminase $4-\mathrm{L}$ was found in 45 out of $80 \mathrm{BPH}$ tissues (Figure 6B). On the other hand, it was only detected in 7 out of 48 $\mathrm{PCa}$ tissues, indicating that the expression of transglutaminase 4- $\mathrm{L}$ decreased in $\mathrm{PCa}$ tissues compared to BPH tissues (Table 2). Nonetheless, transglutaminase 4-L expression did not correlate with serum PSA level, prostate volumes or PSA densities of BPH patients (Table 3).

\section{Discussion}

In this study, we provided the evidence that human transglutaminase 4 is alternatively spliced in prostate tissues. Four mRNA transcripts of transglutaminase 4, designated as transglutaminase 4-L, -M1, -M2 and -S, were identified by RT-PCR and sequence analyses. Identification of transglutaminase $4-\mathrm{L}$ isoform contained a novel exon (exon 2 in Figure 3A) indicates that human trans-

Table 1. Comparison of clinical parameters between BPH and PCa patients.

\begin{tabular}{lcc}
\hline & BPH, Mean \pm SD (range) & PCa, Mean \pm SD (range) \\
\hline Number & 80 & 48 \\
Age (years) & $71 \pm 7.2(51-86)$ & $78 \pm 6(70-91)$ \\
Serum PSA $(\mathrm{ng} / \mathrm{ml})$ & $9.40 \pm 6.96(0.51-29.25)$ & $64.85 \pm 35.09(5.94-126)$ \\
Free PSA (ng/ml) & $2.64 \pm 2.71(0.15-9.42)$ & $14.11 \pm 9.96(0.52-29.57)$ \\
Prostate Volume (cc) & $56.97 \pm 24.30(23-129.5)$ & $49.11 \pm 14.76(35-67.9)$ \\
PSA density (ng/ml/cc) & $0.16 \pm 0.10(0.02-0.39)$ & $1.49 \pm 1.12(0.07-3.46)$ \\
\hline
\end{tabular}


Table 2. Expression of transglutaminase 4 isoforms in $\mathrm{BPH}$ and PCa $(P<0.001)$.

\begin{tabular}{clc}
\hline $\begin{array}{c}\text { Transglutaminase } 4 \\
\text { isoforms }\end{array}$ & BPH (\%) & Prostate Ca. (\%) \\
\hline L \& M & $45(56)$ & $7(15)$ \\
M & $35(44)$ & $41(85)$ \\
& $80(100)$ & $48(100)$ \\
\hline
\end{tabular}

glutaminase 4 gene consists of 15 exons and 14 introns. The novel 45 amino acids corresponding to exon 2 have no significant amino acid sequence similarity with the other member of transglutaminase family. Secondary structure prediction analyses showed that the novel sequences have a long stretch of hydrophobic amino acid residues (about 20 amino acids), which may adopt a turn-helix-turn structural motif.

Both transglutaminase 4-M1 and -M2 does not have exon 2. The generation of transglutaminase 4-M1 or -M2 seems to depend on the selection of a splicing acceptor site during deletion of intron 2 in splicing events. Sequencing of 10 cDNA clones of transglutaminase 4-M showed that the frequency of occurrence of transglutaminase 4-M2 is equal with that of transglutaminase 4-M1 (data not shown), suggesting that transglutaminase 4-M1 and -M2 may be equally expressed in human prostate. However, transglutaminase 4-M2 would use the third initiation codon to produce functional protein product, instead of the first ATG, as described before. It is of interest that the first 10 nucleotides of human transglutaminase 4 (ATGATGGATG) are identical to those of human transglutaminase 1 (Kim et al., 1992, Phillips et al., 1990). Although human transglutaminase 1 also has two variants generated by utilizing different initiation codons, the amino acid sequence difference between two variants is resulted from allelic variation in the human population, instead of an alternative splicing mechanism (Kim et al., 1992).

The presence of several transcripts by alternative splicing may indicate functional diversity of human transglutaminase 4 . However, little is known about its role in the prostate tissue. Interestingly, the clinical sample analyses showed the reduced expression of transglutaminase 4-L in prostate cancer. Thus, our data suggest that the change of alternative splicing of transglutaminase 4 is associated with prostate cancer. Actually, growing evidence indicates that aberrant alternative splicing has been known to be associated with a variety of human diseases, particularly in cancers (Pajares et al., 2007).
A number of alternatively spliced genes have been reported in PCa. PSA is a member of kallikrein gene family and a well-known serum biomarker in PCa. PSA has at least 15 transcripts resulting from alternative splicing and alternative polyadenylation, and they code at least 8 different proteins (Heuze-Vourc'h et al., 2003). The investigation about the changes of these spliced variants in $\mathrm{PCa}$ is required for more specific PSA screening test. Besides PSA, other members of kallikrein gene family, including KLK2, KLK3, KLK11, and KLK15, have more than one spliced variant and were reported to be up-regulated in PCa (Reynolds, 2008). For example, KLK11 has two alternatively spliced isoforms and the low expression of prostate type variant in $\mathrm{PCa}$ is associated with higher tumor stage, Gleason score, and tumor grade (Nakamura et al., 2003). In addition, loss of a certain spliced variant of fibroblast growth factor receptor 2 (FGF-R2) is correlated with androgen insensitivity (Carstens et al., 1997), and truncated isoform of VEGF receptor flt-4 (VEGFR3) increases in PCa with lymph node involvement (Stearns et al., 2004). Therefore, detection of splicing variants can be employed for diagnosis and prognosis prediction in $\mathrm{PCa}$.

While rodent transglutaminase 4 has a crucial role in fertilization by forming copulatory plug, the function of human transglutaminase 4 is still obscure. Since human transglutaminase 4 is secreted form prostate and a constituent of semen, it has been suggested to have a role in human fertilization by suppressing sperm antigenicity or unknown mechanism (Mukherjee et al., 1983, Paonessa et al., 1984). Moreover, transglutaminase 4 showed prostate-restricted expression pattern (Dubbink et al., 1999) and transglutaminase 2, another transglutaminase family member, has been associated with apoptosis and cancer cell survival (Fesus and Szondy, 2005). Therefore, transglutaminase 4 has been suspected to be involved in BPH and PCa pathogenesis. Our result showed loss of transglutaminase 4-L variant in $\mathrm{PCa}$ samples (Table 2), corroborating the previous report that showed down-regulation of

Table 3. Clinical parameters of BPH with or without transglutaminase 4-L.

\begin{tabular}{lccc}
\hline \multicolumn{1}{c}{ Clinical parameter } & $\begin{array}{c}\text { L\& M } \\
(\text { Mean } \pm \text { SD) }\end{array}$ & $\begin{array}{c}\text { M } \\
(\text { Mean } \pm \text { SD) }\end{array}$ & $P$ \\
\hline Serum PSA $(\mathrm{ng} / \mathrm{ml})$ & $9.74 \pm 7.70$ & $9.68 \pm 7.15$ & 0.663 \\
Prostate volume $(\mathrm{cc})$ & $56.31 \pm 24.01$ & $56.51 \pm 25.63$ & 0.805 \\
PSA density $(\mathrm{ng} / \mathrm{ml} / \mathrm{cc})$ & $0.15 \pm 0.11$ & $0.17 \pm 0.11$ & 0.535 \\
\hline
\end{tabular}


transglutaminase 4 expression in metastatic $\mathrm{PCa}$ samples (An et al., 1999). Therefore, down-regulation of transglutaminase 4 , especially transglutaminase 4-L, is probably associated with cancer development and progression. By contrast, recent studies showed that overexpression of transglutaminase 4 in $\mathrm{PCa}$ cells increased adhesion of cancer cells to endothelial cells and reduced barrier function of endothelial cells (Jiang et al., 2009). Conversely, knock-down of transglutaminase 4 in PCa cells decreased invasiveness and tumor-endotheilal cell interactions (Davies et al., 2007; Jiang et al., 2009). Because transglutaminase 4-M1, which is a NCBI reference sequence, was used in these studies, alternatively spliced transglutaminase 4 isoforms could help to explain these contradictory observations on the tumorigenicity and invasiveness of $\mathrm{PCa}$ cells. Nevertheless, the role of each transglutaminase 4 spliced variant in PCa need to be determined.

Although transglutaminase 4 is known as secreted protein, when expressed in HeLa cell, transglutaminase 4-L was not detected in culture supernatants (Figure 5C). Therefore, the difference of cellular localization is one of factors that confer different functions on each spliced variant because enzymes in different location probably use different substrate partners.

In conclusion, we discovered four alternatively spliced variants of transglutaminase 4 (transglutaminase 4-L, -M1, -M2 and -S) and found that loss of transglutaminase 4-L isoform is associated with $\mathrm{PCa}$ in prostate samples. Though the exact pathophysiological functions of these spliced variants need to be determined, these results suggest potential role of transglutaminase 4 in PCa progression and shed light on physiological and pathological functions of human transglutaminase 4 .

\section{Methods}

\section{Prostate specimens and clinical parameters}

Human prostate specimens were obtained from the patients diagnosed to have $\mathrm{BPH}$ or $\mathrm{PCa}$ by transurethral resection of prostate or radical prostatectomy. Tissues were immediately frozen in liquid nitrogen and stored at $-80^{\circ} \mathrm{C}$ until use. H\&E staining of prostate tissues were performed for pathological examination. The study was approved by the Institutional Review Board of Seoul National University Hospital and informed consent was obtained from each patient.

Total and free PSA was assayed from serum of patients using $1^{125}$-labeled anti-PSA monoclonal antibody (ELSAPSA2 kit; CIS-bio Co.). To calculate prostate volume, transrectal ultrasonography was performed using a $\mathrm{HDI}$ 3000 scanner with an endocavitary multifrequency 5- to 9-MHz transducer (ATL Co.). Volume of prostate was calculated using the three main diameters of the gland, in which the volume equals $0.5 \times(L \times W \times H)$, where $L$ is the maximum cephalocaudal length in longitudinal view, $W$ is the maximum transverse length in transaxial view and $H$ is the maximum anteroposterior length in longitudinal view (Terris and Stamey, 1991). The PSA density was calculated as PSA ( $\mathrm{ng} / \mathrm{ml}$ ) divided by prostate volume (cc).

\section{RT-PCR amplification and cloning of human transglutaminase $\mathbf{4}$ isoforms}

Total RNA was isolated from BPH specimens using acid guanidinium thiocyanate-phenol, chloroform extraction method (Chomczynski and Sacchi, 1987). Rapid amplification of cDNA ends (RACE) was employed to amplify the $5^{\prime}$ end of cDNAs (Frohman et al., 1988). Random primed first strand cDNA was synthesized from $500 \mathrm{ng}$ of total RNA by using the Superscript reverse transcriptase kit (Invitrogen), and a stretch of dG residues was added to the $3^{\prime}$ end using terminal deoxynucleotidyl transferase (Promega). The first PCR was performed with $25 \mathrm{pmol}$ of oligo(dC)17 and TP-1 (5'-ctcaaactgaccaaagttcca-3'; reverse) primers using $\mathrm{dG}$ tailed $\mathrm{RT}$ reaction product. The second PCR was performed with a oligo(dC)17 and TP-2 (5'-acaccatgggttgaagaga-3'; reverse) primers as follows. The samples were heated to $95^{\circ} \mathrm{C}$ for $5 \mathrm{~min}$, followed by 35 cycles of denaturation at $94^{\circ} \mathrm{C}(0.5 \mathrm{~min})$, annnealing at $48^{\circ} \mathrm{C}(0.5 \mathrm{~min})$, and extension at $72^{\circ} \mathrm{C}(1.5 \mathrm{~min})$. Following the final extension at $72^{\circ} \mathrm{C}(10 \mathrm{~min}), \mathrm{PCR}$ products were analyzed by $1.5 \%$ agarose gel electrophoresis, purified, and directly ligated into pT7Blue T-vector (Novagen). Colonies containing inserts were selected, and sequenced using primers to the $\mathrm{T} 7$ and $\mathrm{U} 19$ regions of the plasmid vector.

\section{Expression of transglutaminase $\mathbf{4}$ isoforms in yeast and HeLa cells}

cDNAs of transglutaminase 4-L, -M1 and -M2 were cloned into pYES2.0 (Invitrogen) or pcDNA3 (Invitrogen) for expression in yeast or in mammalian cell, respectively. Each transglutaminase 4 isoform was tagged with hemagglutinin epitope for detection of protein. For yeast expression, INVsc1 cells (Invitrogen) were transformed by Lithium acetate/single stranded-DNA/Polyethylglycol method (Jeon et al., 2003) and grown in SD medium $(0.67 \%$ Yeast nitrogen base without amino acids, $2 \%$ glucose and $0.065 \%$ CSM-URA). Expression of protein was induced by incubation with YPG medium (1\% yeast extract, 2\% bacto-peptone and $2 \%$ galactose) for $4 \mathrm{~h}$. For mammalian cell expression, HeLa cells were transfected with transglutaminase 4 isoforms in pcDNA3 using LipofectAMINE reagent (Invitrogen) according to manufacturer's instructions. After $48 \mathrm{~h}$ of transfection, cell lysates and lyophilized culture supernatants were analyzed for protein expression.

\section{Western blot analysis}

Yeast cell was homogenized using glass beads in the homogenization buffer (50 mM Tris-Cl, pH 7.5, $250 \mathrm{mM}$ sucrose, $0.2 \mathrm{mM} \mathrm{MgSO}_{4}, 1 \mathrm{mM}$ EDTA, $10 \mathrm{mM}$ DTT) containing protease inhibitor cockail (Roche). HeLa cells 
were lysed in the buffer containing $50 \mathrm{mM}$ Tris- $\mathrm{Cl}, \mathrm{pH} 8.0$, $150 \mathrm{mM} \mathrm{NaCl}, 1 \%$ Triton $\mathrm{X}-100$ and protease inhibitor cocktail. The culture supernatant of HeLa cells was lyophilized and reconstituted with PBS. The samples were centrifuged at $14,000 \times g$ for $10 \mathrm{~min}$ at $4^{\circ} \mathrm{C}$, and the protein concentration of the supernatant was determined by BCA method. Each sample was resolved by SDS-PAGE and transferred onto nitrocellulose membrane. After treating for $1 \mathrm{~h}$ with $5 \%$ skim milk in Tris-buffered saline, the membrane was incubated with antibodies for hemagglutinin (Roche) or actin (Sigma) for $2 \mathrm{~h}$. The membranes were washed, incubated with HRP-conjugated secondary antibody, and then developed using chemiluminescence substrate solution as instructed by the manufacture (Pierce).

\section{Transglutaminase activity assay}

Transglutaminase activity of yeast lysate was measured by estimating incorporation of $\left[{ }^{14} \mathrm{C}\right]$-putrescine (Amersham) to $\mathrm{N}, \mathrm{N}$ '-dimethylcasein (Sigma). Yeast lysate $(500 \mu \mathrm{g})$ was incubated with $\mathrm{N}, \mathrm{N}^{\prime}$-dimethylcasein and $500 \mathrm{nCi}$ of $\left[{ }^{14} \mathrm{C}\right]$-putrescine in reaction buffer $(50 \mathrm{mM}$ Tris-acetate, $\mathrm{pH}$ 7.5, $10 \mathrm{mM} \mathrm{CaCl}_{2}, 5 \mathrm{mM}$ DTT, $150 \mathrm{mM} \mathrm{NaCl}, 0.5 \%$ Triton $\mathrm{X}-100,0.5 \mathrm{mM}$ EDTA) for $1 \mathrm{~h}$ at $37^{\circ} \mathrm{C}$. After precipitated with trichloroacetic acid, samples were bound to filter paper, and radioreactivity was assessed by scintilation counting. Transglutaminase activity is expressed as a relative value to that of vector transfected cells, which was normalized by protein level of transglutaminase 4 isoforms.

\section{RT-PCR analysis with BPH and PCa specimens}

RNA preparation and reverse transcription were performed using BPH (80 cases) and PCa (48 cases) specimens. PCR was carried out with TP-3 (5'-cactttgttgcccaggctg-3'; forward)/TP-4 (5'-ctgccagttgtagtggtct-3'; reverse), TP-5 (5'agagatagagtcttcctg-3'; forward)/TP-4 and TP-6 (5'-caaacgagcagtcctgtgt-3'; forward)/TP-7 (5'-gcatttgatacttctggca-3'; reverse) for detecting transglutaminase $4-L,-L / M$ and $-M / S$ forms, respectively (Figure 5A). The pre-heated samples were placed in 35 cycles consisting of denaturation at $94^{\circ} \mathrm{C}$ (0.5 min), annnealing at $48^{\circ} \mathrm{C}(0.5 \mathrm{~min})$, and extension at $72^{\circ} \mathrm{C}(1.5 \mathrm{~min})$. Following the final extension at $72^{\circ} \mathrm{C}(10$ $\mathrm{min})$, PCR products were analyzed by $1.5 \%$ agarose gel electrophoresis.

\section{Statistical analysis}

The statistical analyses were performed by the SPSS software (Statistical Package for the Social Sciences, SPSS Inc). Comparison of transglutaminase 4-L expression between $\mathrm{BPH}$ and $\mathrm{PCa}$ was performed with chisquare test. Comparisons of serum PSA, prostate volume and PSA density between transglutaminase 4-L expressed and non-expressed BPH patients were done with the $t$ test. $P$-values less than 0.05 were considered significant.

\section{Acknowledgments}

We thank Dr. Y. D. Kim for critical comments on the manuscript. This work was supported by the grants from Korea
Science and Engineering Foundation (R01-2005-00010364-0) and also by the Research Program for New Drug Target Discovery (M10748000296-07N4800-29610). S.Y.C., E.M.J. and G.Y.J. were supported by the graduate program of BK21, Korean Ministry of Education, Science and Technology.

\section{References}

An G, Meka CS, Bright SP, Veltri RW. Human prostatespecific transglutaminase gene: promoter cloning, tissuespecific expression, and down-regulation in metastatic prostate cancer. Urology 1999;54:1105-11

Blencowe BJ. Alternative splicing: new insights from global analyses. Cell 2006;126:37-47

Carstens RP, Eaton JV, Krigman HR, Walther PJ, GarciaBlanco MA. Alternative splicing of fibroblast growth factor receptor 2 (FGF-R2) in human prostate cancer. Oncogene 1997; 15:3059-65

Chomczynski P, Sacchi N. Single-step method of RNA isolation by acid guanidinium thiocyanate-phenol-chloroform extraction. Anal Biochem 1987;162:156-9

Cukierski MA, Sina JL, Prahalada S, Robertson RT. Effects of seminal vesicle and coagulating gland ablation on fertility in rats. Reprod Toxicol 1991;5:347-52

Davies G, Ablin RJ, Mason MD, Jiang WG. Expression of the prostate transglutaminase (TGase-4) in prostate cancer cells and its impact on the invasiveness of prostate cancer. J Exp Ther Oncol 2007;6:257-64

Dubbink HJ, Verkaik NS, Faber PW, Trapman J, Schroder $\mathrm{FH}$, Romijn JC. Tissue specific and androgen-regulated expression of human prostate-specific transglutaminase. Biochem J 1996;315(Pt 3):901-8

Dubbink HJ, de Waal L, van Haperen R, Verkaik NS, Trapman J, Romijn JC. The human prostate-specific transglutaminase gene (TGM4): genomic organization, tissue-specific expression, and promoter characterization. Genomics 1998;51:434-44

Dubbink HJ, Hoedemaeker RF, van der Kwast TH, Schroder $\mathrm{FH}$, Romijn JC. Human prostate-specific transglutaminase: a new prostatic marker with a unique distribution pattern. Lab Invest 1999;79:141-50

Fesus L, Szondy Z. Transglutaminase 2 in the balance of cell death and survival. FEBS Lett 2005;579:3297-302

Frohman MA, Dush MK, Martin GR. Rapid production of full-length cDNAs from rare transcripts: amplification using a single gene-specific oligonucleotide primer. Proc Natl Acad Sci USA 1988;85:8998-9002

Grant FJ, Taylor DA, Sheppard PO, Mathewes SL, Lint W, Vanaja E, Bishop PD, O'Hara PJ. Molecular cloning and characterization of a novel transglutaminase cDNA from a human prostate cDNA library. Biochem Biophys Res Commun 1994;203:1117-23

Griffin M, Casadio R, Bergamini CM. Transglutaminases: nature's biological glues. Biochem J 2002;368:377-96 
Heuze-Vourc'h N, Leblond V, Courty Y. Complex alternative splicing of the hKLK3 gene coding for the tumor marker PSA (prostate-specific-antigen). Eur J Biochem 2003;270:70614

Ho KC, Quarmby VE, French FS, Wilson EM. Molecular cloning of rat prostate transglutaminase complementary DNA. The major androgen-regulated protein DP1 of rat dorsal prostate and coagulating gland. J Biol Chem 1992; 267:12660-7

Jeon JH, Choi KH, Cho SY, Kim CW, Shin DM, Kwon JC, Song KY, Park SC, Kim IG. Transglutaminase 2 inhibits Rb binding of human papillomavirus $\mathrm{E} 7$ by incorporating polyamine. EMBO J 2003;22:5273-82

Jiang WG, Ablin RJ, Kynaston HG, Mason MD. The prostate transglutaminase (TGase-4, TGaseP) regulates the interaction of prostate cancer and vascular endothelial cells, a potential role for the ROCK pathway. Microvasc Res 2009;77:150-7

Kim IG, McBride OW, Wang M, Kim SY, Idler WW, Steinert $P M$. Structure and organization of the human transglutaminase 1 gene. J Biol Chem 1992;267:7710-7

Lorand L, Graham RM. Transglutaminases: crosslinking enzymes with pleiotropic functions. Nat Rev Mol Cell Biol 2003;4:140-56

Mount SM. A catalogue of splice junction sequences. Nucleic Acids Res 1982;10:459-72

Mukherjee DC, Agrawal AK, Manjunath R, Mukherjee AB. Suppression of epididymal sperm antigenicity in the rabbit by uteroglobin and transglutaminase in vitro. Science 1983; 219:989-91

Nakamura T, Stephan C, Scorilas A, Yousef GM, Jung K, Diamandis EP. Quantitative analysis of hippostasin/KLK11 gene expression in cancerous and noncancerous prostatic tissues. Urology 2003;61:1042-6

Pajares MJ, Ezponda T, Catena R, Calvo A, Pio R, Montuenga LM. Alternative splicing: an emerging topic in molecular and clinical oncology. Lancet Oncol 2007;8: 349-57

Paonessa G, Metafora S, Tajana G, Abrescia P, De Santis A, Gentile V, Porta R. Transglutaminase-mediated modifications of the rat sperm surface in vitro. Science 1984; 226:852-5

Phillips MA, Stewart BE, Qin Q, Chakravarty R, Floyd EE, Jetten AM, Rice RH. Primary structure of keratinocyte transglutaminase. Proc Natl Acad Sci USA 1990;87:9333-7

Reynolds MA. Molecular alterations in prostate cancer. Cancer Lett 2008;271:13-24

Savli H, Szendröi A, Romics I, Nagy B. Gene network and canonical pathway analysis in prostate cancer: a microarray study. Exp Mol Med 2008;40:176-85

Seitz J, Keppler C, Rausch U, Aumuller G. Immunohistochemistry of secretory transglutaminase from rodent prostate. Histochemistry 1990;93:525-30

Stearns ME, Wang M, Hu Y, Kim G, Garcia FU. Expression of a flt-4 (VEGFR3) splicing variant in primary human prostate tumors. VEGF D and flt-4t(Delta773-1081) overexpression is diagnostic for sentinel lymph node metastasis. Lab Invest 2004;84:785-95

Terris MK, Stamey TA. Determination of prostate volume by transrectal ultrasound. J Urol 1991;145:984-7

Williams-Ashman HG. Transglutaminases and the clotting of mammalian seminal fluids. Mol Cell Biochem 1984;58:51-61

Williams-Ashman HG, Notides AC, Pabalan SS, Lorand L. Transamidase reactions involved in the enzymic coagulation of semen: isolation of -glutamyl- -lysine dipeptide from clotted secretion protein of guinea pig seminal vesicle. Proc Natl Acad Sci USA 1972;69:2322-5

Williams-Ashman HG, Wilson J, Beil RE, Lorand L. Transglutaminase reactions associated with the rat semen clotting system: modulation by macromolecular polyanions. Biochem Biophys Res Commun 1977;79:1192-8 